\title{
Heterotrophic nanoflagellates and increased essential fatty acids during Microcystis decay
}

\author{
Sangkyu Park ${ }^{1,5, *}$, Michael T. Brett ${ }^{2}$, Dörthe C. Müller-Navarra ${ }^{3}$, Sang-Cheon Shin ${ }^{4}$, \\ Anne M. Liston ${ }^{1}$, Charles R. Goldman ${ }^{1}$ \\ ${ }^{1}$ Department of Environmental Science and Policy, University of California, 1 Shields Avenue, Davis, California 95616, USA \\ ${ }^{2}$ Department of Civil and Environmental Engineering, University of Washington, Box 352700, 301 More Hall, Seattle, Washington 98195, USA \\ ${ }^{3}$ Institut für Hydrobiologie und Fischereiwissenschaft, Abteilung Biologische Ozeanographie, Universität Hamburg, Olbersweg 24, \\ 22767 Hamburg, Germany \\ ${ }^{4}$ Geyongsangbuk-do Provincial Institute of Health and Environment, Deagu, 702-702, South Korea \\ ${ }^{5}$ Present address: West Sea Fisheries Research Institute, San 66-3, Eulwang-dong, Jung-gu, Incheon 400-420, South Korea
}

\begin{abstract}
To investigate the potential for heterotrophic organisms to upgrade the food quality of seston, we performed decay experiments using a non-toxic Microcystis aeruginosa (cyanobacteria) monoculture. The experiment was performed in darkness with aeration using a microbial inoculum collected from a hypereutrophic pond. Chlorophyll a concentrations decreased throughout the decay experiment. In contrast, eicosapentaenoic acid (EPA, 20:5 03 ) and docosahexaenoic acid (DHA, 22:6 $\omega 3$ ) concentrations increased and peaked on Day 5 , while $\alpha$-linolenic acid $(\alpha$-LA, 18:3 $\omega 3)$ and

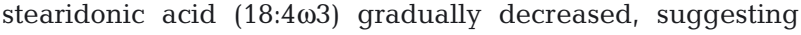
that EPA and DHA might be converted from $\alpha$-LA and stearidonic acid. Microscopic examination revealed that a heterotrophic nanoflagellate (HNF) and the ciliate Vorticella sp. dominated the biological community during this experiment. Further examination using scanning electron microscopy (SEM) identified the HNF as Paraphysomonas vestita ssp. vestita, whose biovolume was very strongly correlated with EPA concentrations. Size-fractionized fatty acid determinations carried out on Day 6 showed that approximately twothirds of the seston's total EPA content was in the $<5 \mu \mathrm{m}$ size fraction, which corresponded to the $P$. vestita size fraction. This size fraction also had a fatty acid content (relative to carbon content) 3 times higher than the 5 to 10 or $>10 \mu \mathrm{m}$ seston size fractions.
\end{abstract}

KEY WORDS: Trophic upgrading · Essential fatty acids $\cdot$ Food quality $\cdot$ Microcystis $\cdot$ Decaying $\cdot$ Paraphysomonas

Resale or republication not permitted without written consent of the publisher

The traditional paradigm envisions most energy flow occurring through the classic food chain (i.e. phytoplankton, zooplankton, and zooplanktivorous fish) with the microbial food web playing its most important role via nutrient regeneration (Lampert \& Sommer
1993). The flow of energy between phytoplankton and zooplankton (i.e. the plant-animal interface in planktonic systems) is highly variable, as phytoplankton food quality for zooplankton ranges from very low to very high. Recently, the factors determining seston (suspended particles in the natural water including phytoplankton, ciliates, heterotrophic nanoflagellates [HNF], bacteria, and detritus) food quality for herbivorous zooplankton have been intensively studied (see Brett \& Müller-Navarra 1997 and Sterner \& Shulz 1998 for reviews), and seston essential fatty acid (MüllerNavarra 1995) and phosphorus (Urabe \& Watanabe 1992) content were found to explain variation in seston food quality. In the past, microbial food webs have been regarded as a link between macrozooplankton with detrital food sources through 'trophic repackaging' (Gifford 1991), i.e. packing smaller particles into larger more easily ingestable particles. However, changes in the biochemical composition of these particles were not considered. More recently, it has been suggested that organisms of the microbial food web such as heterotrophic dinoflagellates contribute $\omega 3$-polyunsaturated fatty acids ( $\omega 3$-PUFA) to marine planktonic systems by converting low food quality fatty acids to $\omega 3$-PUFA. This 'trophic upgrading' scenario (Klein Breteler et al. 1999) suggests that overall food quality of seston can be enhanced even though low quality phytoplankton, such as cyanobacteria, are at the base of the food chain. Furthermore, several studies report that decaying cyanobacteria such as Microcystis and Oscillatoria may be higher quality food for freshwater cladocerans than these same cultures in 
their healthy state (Hanazato 1991, Repka et al. 1998). Here, we report that a HNF appeared to enhance the food quality of decaying Microcystis aeruginosa for herbivorous zooplankton by upgrading $\omega 3$-PUFA.

Materials and methods. For the experiment, we used the Microcystis aeruginosa strain UTEX 2386, a unicellular strain that does not form colonies when healthy. $M$. aeruginosa were batch cultured using the synthetic medium L16 (Lindström 1983) modified with vitamins ( $\mathrm{B}_{12}$, biotin and thiamin), and potting soil extract. For the decaying procedure, we aerated 31 of $M$. aeruginosa in 41 Erlenmeyer flasks that were wrapped completely with aluminum foil and incubated in the dark according to Hanazato \& Yasuno (1987). At the start of the experiment, $100 \mathrm{ml}$ of water from hypereutrophic Lake Spafford on the University of California-Davis campus was used as a microbial food web inoculum (hereafter designated the microbial inoculum). We used 4 flasks for each experiment. Three flasks received this microbial inoculum and one (the control) did not. The experiment lasted $7 \mathrm{~d}$ and was carried out in a temperature-controlled room at $20^{\circ} \mathrm{C}$. On Day 6, we collected approximately $500 \mathrm{ml}$ from each flask except for the control for fractionization of fatty acid and carbon quantity with 5 and $10 \mu \mathrm{m}$ screen $\left(\mathrm{Nitex}^{\circledR}\right.$ nylon bolt cloth). We collected samples for the enumeration and measurement of phytoplankton/ciliates/HNF and quantification of fatty acids, particulate carbon and chlorophyll a (chl a). Phytoplankton/ciliate/HNF samples were preserved in $1 \%$ Lugol's solution, counted and measured with an inverted microscope using the Utermöhl technique (Utermöhl 1958). The total biovolumes of these organisms were converted into carbon using the following allometric equation: carbon $(\mathrm{pg})=a \times$ cell volume $\left(\mu^{3}\right)^{3}$, where $a=0.11$ for ciliates and 0.22 for HNF (Gaedke 1992). Phytoplankton ( $M$. aeruginosa) carbon was estimated from the relationship between particulate carbon and chl a concentrations in samples from Day 0 and in the control samples without a microbial inoculum. For chl a determination, $10 \mathrm{ml}$ of the sample was filtered through glass fiber filters (Whatman GF/C), and measured using the fluorometric method with acid correction after methanol extraction (Marker et al. 1980). For fatty acid analyses, $250 \mathrm{ml}$ was filtered onto precombusted Whatman GF/C filters, which were then stored at $\leq-80^{\circ} \mathrm{C}$ until extraction. Extraction and methylation were performed according to Kattner \& Fricke (1986). We used $10 \mu \mathrm{l}$ of heneicosanoic acid $\left(21: 0,1 \mathrm{mg} \mathrm{ml}^{-1}\right)$ as an internal standard, which was added to the freeze-dried samples immediately prior to the extraction process. These samples were analyzed with a gas chromatograph (HP6890) with a Programmable-Temperature-Vaporizer and a Flame-Ionization-Detector. Fatty acids were quantified by comparing the area ratios of samples to the internal standard. Response factors for the single fatty acid standards were obtained by comparing quantitative fatty acid standards with the internal standard. The differences between estimated fatty acid concentrations from the internal standard and quantitative standards were smaller than $5 \%$. For particulate carbon analyses, $50 \mathrm{ml}$ was filtered onto $13 \mathrm{~mm}$ Whatman GF/C filters. These filters were dried at $60^{\circ} \mathrm{C}$ for $2 \mathrm{~d}$, wrapped with aluminum foil, and then analyzed using an automatic carbon and nitrogen analyzer (ANCA-GSL and 20-20 mass spectrometer, Europa Scientific).

For scanning electron microscope (SEM) examination, live HNF were harvested on Day 5 using a $10 \mu \mathrm{m}$ screen $\left(\mathrm{Nitex}^{\oplus}\right)$ and $3 \mu \mathrm{m}$ polycarbonate membrane filter (Nucleopore) in an independent decay experiment where we followed the same experimental protocol. This HNF species appeared to be identical under a light microscope at $\times 600$ to the HNF in the experiment described above. In preparation for the SEM, the sample was fixed in $2.5 \%$ glutaraldehyde and $2 \%$ paraformaldehyde in a $0.1 \mathrm{M}$ phosphate buffer, $\mathrm{pH} 7.4$, rinsed in the same phosphate buffer and quickly transferred to $100 \%$ ethanol with 2 changes before placing it in the critical point drier (Pelco Model CPD-2). Drying was carried out using bone-dry grade $\mathrm{CO}_{2}$. Specimens were then positioned on aluminum stubs using silver paint as the adhesive. Once thoroughly air-dried, they were sputter-coated with gold (Pelco Model SC-7). Samples were viewed in a SEM (Philips XL 30) operated at $10 \mathrm{kV}$.

Results. In the control treatment, chl a concentrations increased from $107 \mu \mathrm{g} \mathrm{l}^{-1}$ on Day 0 to $177 \mu \mathrm{g} \mathrm{l}^{-1}$ on Day 2, but remained fairly constant for the remainder of the experiment (Fig. 1A). This suggests that Microcystis aeruginosa did not decompose in the absence of inoculum. There were no major changes in the PUFA concentrations observed in this treatment (Fig. 1A).

In contrast, Microcystis aeruginosa continued to decompose in the treatment with the microbial inoculum. This was indicated by a decrease in chl a concentration and the formation of aggregated and deformed colonies. PUFA such as eicosapentaenoic acid (EPA,

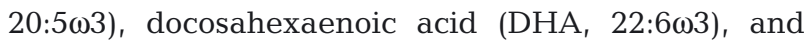

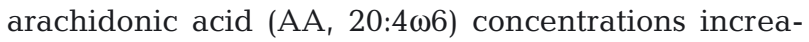
sed and peaked on Day 5 , while $\alpha$-linolenic acid ( $\alpha$-LA,

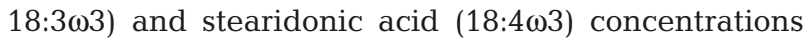
decreased gradually from Day 3 through the remainder of the experiment (Fig. 1B). Chl a concentrations declined to $15.5 \%$ of the initial value by Day 7 (Fig. 1C). Microscopic examination revealed that a HNF and the ciliate Vorticella sp. dominated the biological community (Fig. 1C). Further examination using a SEM revealed that the HNF was Paraphysomonas vestita ssp. vestita (Preisig \& Hibberd 1982a,b) 

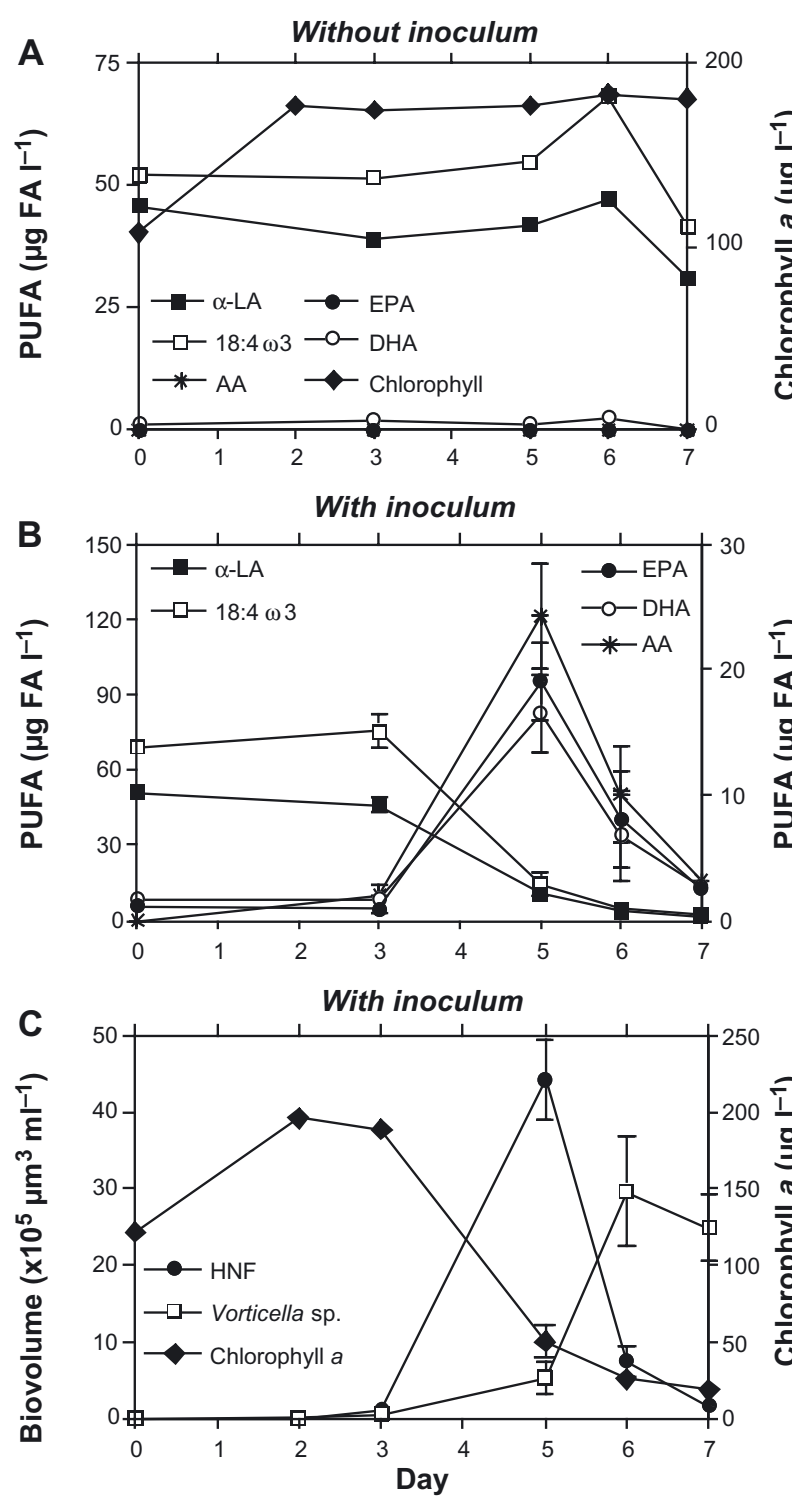

Fig. 1. Major changes in polyunsaturated fatty acid concentration (A) without decomposer inoculum and (B) with decomposer inoculum, and (C) biological change during the experiment. Error bars in $(B)$ and $(C)$ indicate mean \pm SE $(n=3)$. Panel (A) does not have standard error bar because there were no replications $(n=1)$. In (B), left $y$-axis is for $\alpha$-linolenic acid $(\alpha$-LA) and stearidonic acid $(18: 4 \omega 3)$ while right $y$-axis is for eicosapentaenoic acid (EPA), docosahexaenoic acid (DHA) and arachidonic acid (AA)

(Fig. 2). The longest dimension for the $P$. vestita was on average $6.4 \pm 0.9 \mu \mathrm{m}$ (mean $\pm \mathrm{SD}, \mathrm{n}=52$ ) while the longest dimension for Vorticella sp. was on average $35.5 \pm 4.3 \mu \mathrm{m}$ (mean $\pm \mathrm{SD}, \mathrm{n}=51$ ). The sum of carbon estimated from the respective biovolume for $P$. vestita, Vorticella sp. and $M$. aeruginosa was collectively $129 \%$ (Day 5), 106\% (Day 6), and 78\% (Day 7) of the measured total particulate carbon. The biovolume of $P$. vestita in these experiments was very strongly corre- lated with EPA concentrations $\left(r^{2}=0.86\right.$; Fig. 3). Size fractionization of Day 6 fatty acid samples revealed that the $<5 \mu \mathrm{m}$ size fraction comprised approximately two-thirds of total PUFA (Fig. 4A). In addition, the $<5 \mu \mathrm{m}$ size fraction had a relative fatty acid content (normalized to carbon biomass) 3 times higher on average than did the 5 to 10 or $>10 \mu \mathrm{m}$ size fractions (Fig. 4B).

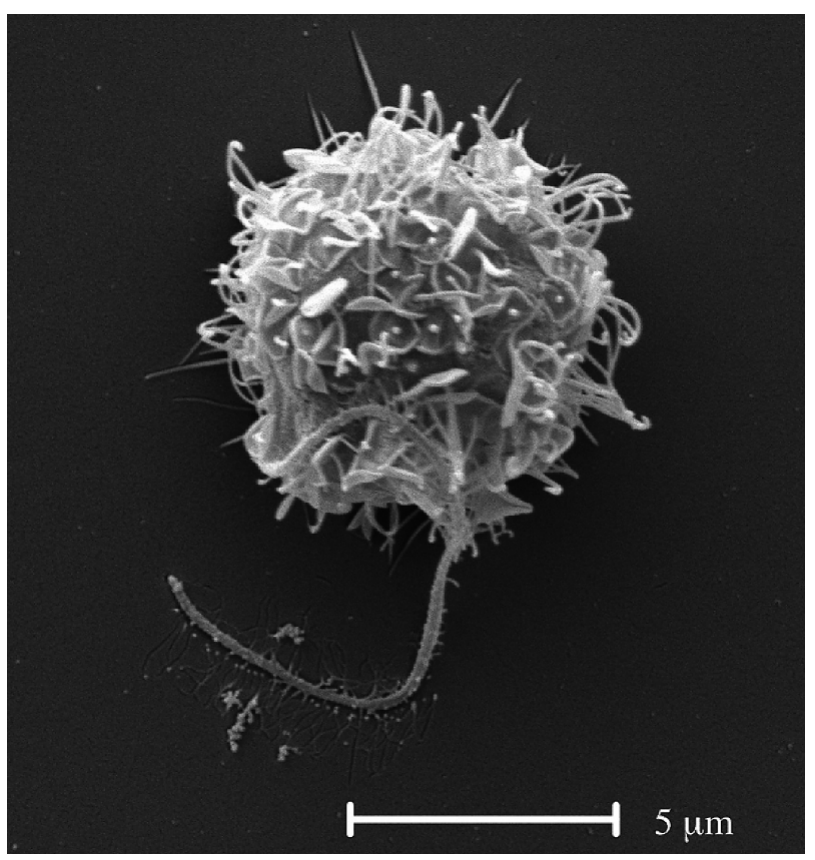

Fig. 2. Paraphysomonas vestita ssp. vestita. Scanning electron microscopy (SEM) image of the heterotrophic nanoflagellate at $\times 7600$

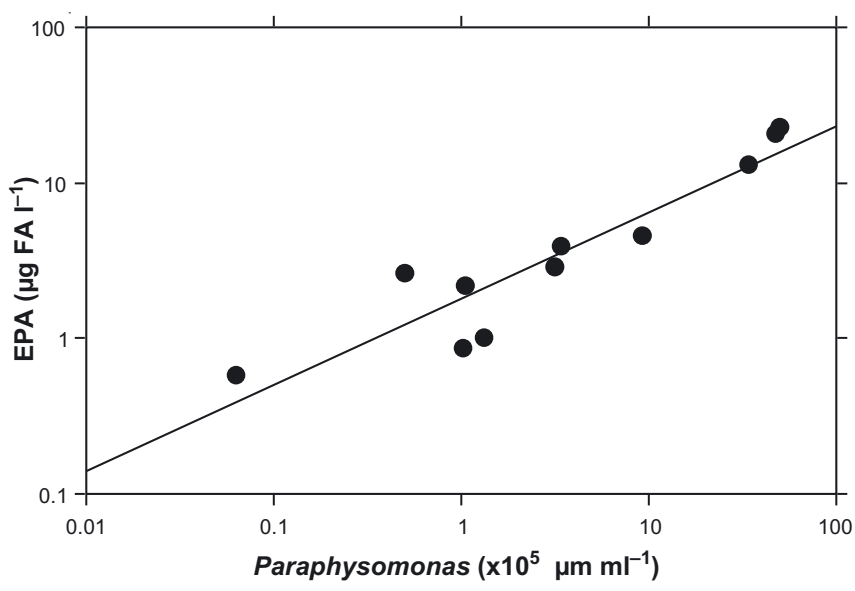

Fig. 3. Paraphysomona vestita. Relationship between biovolume of the heterotrophic nanoflagellate and the EPA concentration during the experiment. The $P$. vestita biovolumes and EPA concentrations were log-transformed to normalize their distributions. Equation for the regression line is as follows: EPA = $1.819 \times$ Paraphysomonas $^{0.555}\left(\mathrm{n}=17, \mathrm{r}^{2}=0.86\right)$. FA: fatty acid 

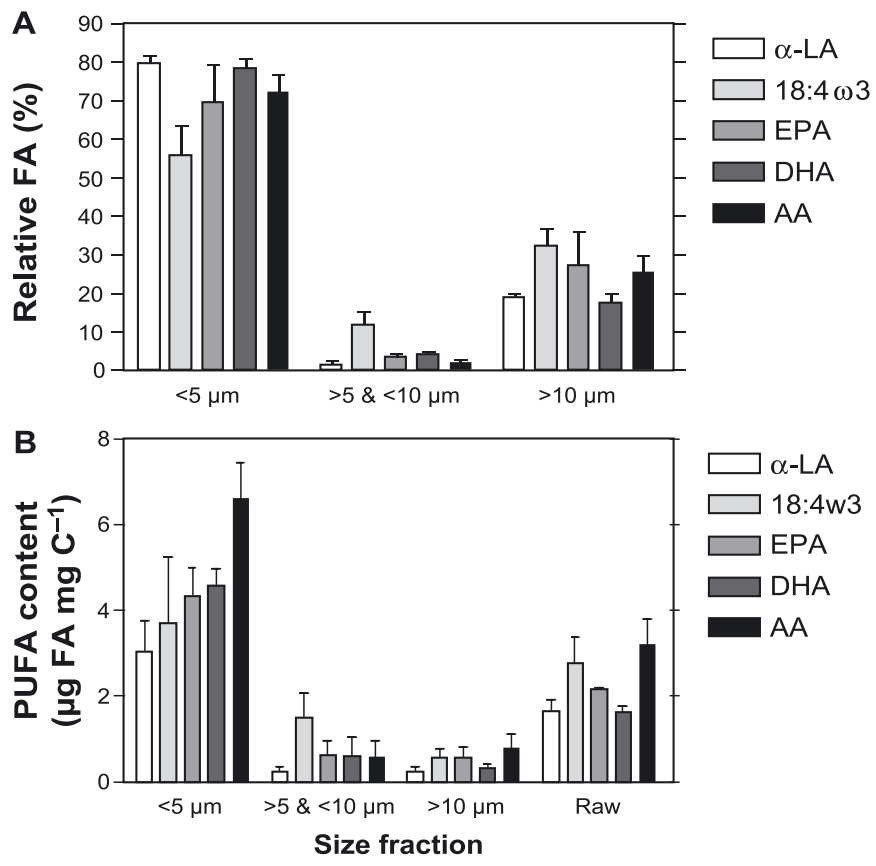

Fig. 4. (A) Relative fatty acid (FA) concentrations compared to the raw (unscreened) concentrations and (B) FA content on Day 6. Error bars indicate mean $\pm \operatorname{SE}(n=3)$

Discussion. Our results show that the microbial decay of Microcystis aeruginosa by a microbial inoculum from the field was accompanied by increases in the concentrations of the highly unsaturated fatty acids EPA and DHA. Since the $M$. aeruginosa culture in our experiment contained very little EPA or DHA to begin with, these EPA and DHA increases can be attributed to protozoans in the pond water inoculum. The extremely high correlation between EPA concentrations and Paraphysomonas vestita biovolume suggests that this HNF caused the increase of EPA and DHA during the experiment. $P$. vestita appeared to contain the majority of the EPA and DHA on Day 6, assuming that most $P$. vestita cells passed through the $5 \mu \mathrm{m}$ mesh screen due to their flexible cell morphology and pressure from the vacuum pump and that $M$. aeruginosa, Vorticella sp., and P. vestita contributed almost all seston carbon. Bacteria are generally thought not to produce PUFA (Napotalino 1999).

Paraphysomonas vestita is a heterotrophic heterokont flagellate (a flagellate with 2 different flagella) and is closely related to heterokonts with chloroplasts such as autotrophic chrysophytes (Preisig et al. 1991). Very few studies have examined the fatty acid composition of chrysophyte algae or heterotrophic heterokont flagellates in particular. Cranwell et al. (1988) reported that some freshwater chrysophytes contained considerable amounts of $\omega 3$-PUFA (14 to $42 \%$ of total fatty acids). In addition, the heterotrophic marine flagellate
Bodo sp. was reported to be capable of synthesizing PUFA, especially DHA (Zhukova \& Kharlamenko 1999). However, Véra et al. (2001) reported that cultures of the heterotrophic flagellates $P$. vestita and Spumella pudica did not contain significant amounts of $\omega 3$-PUFA ( $\leq 2 \%$ of total fatty acids by weight) when grown on bacteria and growth medium enriched with organic matter. Due to the sparse information available on fatty acid metabolism in heterotrophic flagellates, it is unclear how P. vestita in the present study produced EPA and DHA. Since Microcystis aeruginosa contained a considerable amount of $\alpha$-LA and

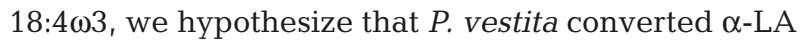

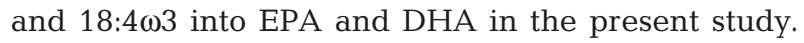
This is supported by the strong decline in $\alpha$-LA and 18:4 $\omega 3$ concentrations (Fig. 1B) that occurred at the same time that EPA and DHA concentrations increased in this experiment. As $P$. vestita was previously reported not to contain significant amounts of $\omega 3$-PUFA (Véra et al. 2001, Bec et al. 2003a), we consider that $P$. vestita might produce EPA and DHA only when precursors such as $\alpha$-LA and 18:4 103 are available.

There are several possible mechanisms through which Paraphysomonas vestita may obtain $\alpha$-LA and

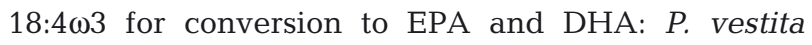
obtains $\alpha$-LA and 18:4 13 (1) directly from feeding on live Microcystis aeruginosa, (2) from feeding on dead M. aeruginosa or bacteria, or (3) directly from the water after they have been released from $M$. aeruginosa through the decay process. We favor the second possibility since our results showed that EPA and DHA production took place only after chl a began to decline (i.e. $M$. aeruginosa began to decay) and $P$. vestita are known to be phagotrophic (Moestrup \& Anderson 1991). However, we cannot exclude the possibility that $P$. vestita feed on live $M$. aeruginosa (cell diameter: $5 \mu \mathrm{m})$ since it has been reported that $P$. vestita selectively feed on chroococcoid cyanobacteria (Synechococcus sp.) and nanoflagellates (Spumella sp.) over bacteria (Müller 1996) and Paraphysomonas feed on phytoplankton of similar size (Sherr \& Sherr 1994).

Our results may have important implications, as past research which has shown that phytoplankton of high food quality tend to have high EPA concentrations (Ahlgren et al. 1990) and that daphnid growth can be predicted by the EPA content of their seston food (Müller-Navarra 1995, Brett \& Müller-Navarra 1997, Müller-Navarra et al. 2000). In addition, Ravet et al. (2003) demonstrated that supplementing cyanobacteria of low food quality with the single fatty acid EPA significantly enhanced Daphnia pulex growth and reproduction and accounted for $37 \%$ of the difference in food quality between cyanobacteria and cryptophytes of high food quality. Supplementing cyano- 
bacteria with 5 fatty acids (including EPA, DHA, $\alpha$-LA

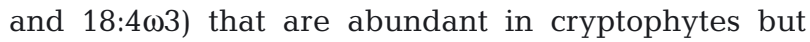
nearly absent in cyanophytes accounted for about $55 \%$ of the difference in food quality between these phytoplankton groups.

Our results suggest that the food quality of decaying Microcystis aeruginosa is enhanced by the activities of microbial food web organisms with increased EPA and DHA concentrations, supporting a recent report that heterotrophic flagellates upgraded the biochemical composition of its algal food sources (Bec et al. 2003b). This subsidy to the classical food web by the microbial food web might increase the biomass transfer between seston and consumers such as zooplankton and zoobenthos in freshwater ecosystems.

Acknowledgements. This work was supported by National Science Foundation Grant DEB-0075591. We thank K. ButlerDeRose and G. Adamson for sample preparation and training for scanning electron microscopy, A. French for help conducting the decay experiments, T. Corliss for processing the SEM images, and R. Henery and G. Malyj for constructive comments on the manuscript.

\section{LITERATURE CITED}

Ahlgren G, Lundstedt L, Brett MT, Forsberg C (1990) Lipid composition and food quality of some freshwater phytoplankton for cladoceran zooplankters. J Plankton Res 12: 809-818

Bec A, Desvilettes C, Véra A, Fontvielille D, Bourdier G (2003a) Nutritional value of different food sources for the benthic Daphnidae Simocephalus vetulus: role of fatty acids. Arch Hydrobiol 156:145-163

Bec A, Desvilettes C, Véra A, Lemarchand C, Fontvieille D, Bourdier G (2003b) Nutritional quality of a freshwater heterotrophic flagellate: trophic upgrading of its microalgal diet for Daphnia hyalina. Aquat Microb Ecol 32:203-207

Brett MT, Müller-Navarra DC (1997) The role of highly unsaturated fatty acids in aquatic food web processes. Freshw Biol 38:483-499

Cranwell PA, Creighton ME, Jaworski GHM (1988) Lipids of four species of freshwater chrysophytes. Phytochemistry 27:1053-1059

Gaedke U (1992) The size distribution of planktonic biomass in a large lake and its seasonal variability. Limnol Oceanogr 37:1202-1220

Gifford DJ (1991) The protozoan-metazoan trophic link in pelagic ecosystems. J Protozool 38:81-86

Hanazato T (1991) Interrelations between Microcystis and cladocera in the highly eutrophic Lake Kasumigaura, Japan. Int Rev Ges Hydrobiol 76:21-36

Hanazato T, Yasuno M (1987) Evaluation of Microcystis as food for zooplankton in a eutrophic lake. Hydrobiologia 144:251-259

Kattner G, Fricke HSG (1986) Simple gas-liquid chromatographic method for the simultaneous determination of fatty acids and alcohols in wax esters of marine organisms. J Chromatogr 361:263-268

Klein Breteler WCM, Schogt N, Baas M, Schouten S, Kraay

Editorial responsibility: John Dolan,

Villefranche-sur-Mer, France
GW (1999) Trophic upgrading of food quality by protozoans enhancing copepod growth, role of essential lipids. Mar Biol 135:191-198

Lampert W, Sommer U (1993) Limnoecology — the ecology of lakes and streams. Translated by JF Hanley in 1997. Oxford University Press, New York

Lindström K (1983) Selenium as a growth factor for plankton algae in laboratory experiments and in some Swedish lakes. Hydrobiologia 101:35-48

Marker AF, Crowther CA, Gunn RJM (1980) Methanol and acetone as solvents for estimating chlorophyll a and pheopigments by spectrometry. Arch Hydrobiol Beih Ergebn Limnol 14:52-59

Moestrup Ø, Anderson RA (1991) Organization of heterotrophic heterokonts. In: Patterson DJ, Larsen J (eds) The biology of free-living heterotrophic flagellates. Clarendon Press, Oxford, p 333-360

Müller H (1996) Selective feeding of a freshwater chrysomonad, Paraphysomonas sp., on chroococcoid cyanobacteria and nanoflagellate. Arch Hydrobiol Spec Iss Adv Limnol 48:63-71

Müller-Navarra DC (1995) Evidence that a highly unsaturated fatty acid limits Daphnia growth in nature. Arch Hydrobiol 132:297-307

Müller-Navarra DC, Brett MT, Liston AM, Goldman CR (2000) A highly unsaturated fatty acid predicts carbon transfer between primary producers and consumers. Nature 403:74-77

Napotalino GE (1999) Fatty acids as trophic and chemical markers. In: Arts MT, Wainman BC (eds) Lipids in freshwater ecosystems. Springer, New York, p 21-44

Preisig HR, Hibberd DJ (1982a) Ultrastructure and taxonomy of Paraphysomonas (Chrysophyceae) and related genera. 1. Nord J Bot 2:397-420

Preisig HR, Hibberd DJ (1982b) Ultrastructure and taxonomy of Paraphysomonas (Chrysophyceae) and related genera. 2. Nord J Bot 2:601-638

Preisig HR, Vørs N, Hällfors G (1991) Diversity of heterotrophic heterokont flagellates. In: Patterson DJ, Larsen J (eds) The biology of free-living heterotrophic flagellates. Clarendon Press, Oxford, p 361-399

Ravet JL, Brett MT, Müller-Navarra DC (2003) A test of the role of polyunsaturated fatty acids in algal food quality for Daphnia using liposome supplementation. Limnol Oceanogr (in press)

Repka S, Van der Vlies M, Vijverberg J (1998) Food quality of detritus derived from the filamentous cyanobacterium Oscillatoria limnetica for Daphnia galeata. J Plankton Res 20:2199-2205

Sherr EB, Sherr BF (1994) Bacterivory and herbivory: key roles of phagotrophic protests in pelagic food webs. Microb Ecol 28:223-235

Sterner RW, Schulz KL (1998) Zooplankton nutrition, recent progress and a reality check. Aquat Ecol 32:261-279

Urabe J, Watanabe Y (1992) Possibility of N or P limitation for planktonic cladocerans: an experimental test. Limnol Oceanogr 37:244-251

Utermöhl H (1958) Zur Vervollkommnung der quantitativen Phytoplankton-Methodik. Mitt Int Ver Limnol 9:1-38

Véra A, Desvilettes C, Bec A, Bourdier G (2001) Fatty acid composition of freshwater heterotrophic flagellates: an experimental study. Aquat Microb Ecol 25:271-279

Zhukova NV, Kharlamenko VI (1999) Sources of essential fatty acids in the marine microbial loop. Aquat Microb Ecol 17:153-157

Submitted: June 4, 2003; Accepted: September 1, 2003

Proofs received from author(s): September 28, 2003 